\title{
Cultural adaptation of the Glamorgan Scale to Brazilian Portuguese: Pressure Injury in Pediatrics*
}

\author{
Marcelli Cristine Vocci ${ }^{1,2}$ \\ (D) https://orcid.org/0000-0003-0029-139x \\ Cassiana Mendes Bertoncello Fontes \\ (1) https://orcid.org/0000-0002-6579-8637 \\ Luciana Patricia Fernandes Abbade ${ }^{1}$ \\ (D) https://orcid.org/0000-0002-0334-2079
}

\begin{abstract}
Paper extracted from doctoral dissertation "Tradução e adaptação transcultural da Glamorgan Scale: comparação preditiva com a Escala de Braden Q", presented to Universidade Estadual Paulista, Faculdade de Medicina de Botucatu, Botucatu, SP, Brazil. This study was financed in part by the Coordenação de Aperfeiçoamento de Pessoal de Nível Superior - (CAPES) - Finance Code 001, Grant \# 88882.433308/2019-01, Brazil.

Universidade Estadual Paulista, Faculdade de Medicina de Botucatu, Botucatu, SP, Brazil.

2 Scholarship holder at the Coordenação de Aperfeiçoamento de Pessoal de Nível Superior (CAPES), Brazil.
\end{abstract}

Objective: to describe the methodological process of cultural adaptation of the Glamorgan Scale to Brazilian Portuguese.

Method: a methodological study of translation and cultural adaptation of the Glamorgan Scale, following the six stages: initial translation, synthesis of translations, back-translation, committee of experts, pre-test, and submission of the adapted version to the author for approval. The committee of experts was composed of five physicians and, during evaluation, a semantic, idiomatic, cultural and conceptual analysis was carried out. The agreement and representativeness of the items were assessed using the Content Validity Index. A minimum value of $80 \%$ agreement was considered. Results: all stages of the translation and cross-cultural adaptation process were satisfactory. In the evaluation made by the committee of experts, all items obtained an agreement greater than $80 \%$ in the first evaluation round. The pre-test stage allowed for a critical overview of the instrument, where few modifications were suggested by the participants. Conclusion: the Glamorgan Scale was translated and culturally adapted to Brazilian Portuguese. Future psychometric studies are necessary to validate the scale.

Descriptors: Translating; Transcultural Studies; Nursing Methodology Research; Pressure Ulcer; Quality of Health Care; Pediatric Nursing.

\section{How to cite this article}

Vocci MC, Fontes CMB, Abbade LPF. Cultural adaptation of the Glamorgan Scale to Brazilian Portuguese: Pressure Injury in Pediatrics. Rev. Latino-Am. Enfermagem. 2021;29:e3424. [Access $\frac{1}{1}$ - ]; Available in: DOI: http://dx.doi.org/10.1590/1518-8345.4083.3424. 


\section{Introduction}

Pressure Injury (PI) is localized damage to the underlying skin and/or soft tissues, usually on a bony prominence or related to the use of a medical device or other device. It occurs as a result of intense and/or prolonged pressure in combination with shear ${ }^{(1)}$. This condition imposes physical and psychological burdens on the patients and their families and can cause discomfort, pain, impaired quality of life, prolonged hospital stay (a mean of four days $\left.{ }^{(2)}\right)$ and, in severe cases, infected PIs can lead to osteomyelitis $^{(3)}$. In addition, it is related to high mortality rates $^{(4-5)}$, to an increase in the workload of professionals, and to a significant increase in costs for institutions ${ }^{(6-7)}$.

Thus, in the search for improving care, indicators have been studied and, among them, PI stands out as part of the set of quality indicators related to Nursing care processes. In 2010, through the São Paulo Regional Nursing Board, a booklet was launched with the "10 steps for patient safety"(8), one of which is the prevention of PI. In addition, reducing the risk and incidence of PI has become one of the six patient safety goals, and one of the priorities of the Ministry of Health ${ }^{(9)}$.

The prevention of PI requires prior and accurate identification of the risk score of each patient and, related to this, it is essential to implement a set of preventive measures. The availability of reliable instruments that predict the risk of critical pediatric patients developing $\mathrm{PI}^{(10-11)}$ is crucial to this process.

For this, the methodological processes ${ }^{(12)}$ of translation and cultural adaptation are essential when the intention is to use an instrument previously developed by researchers from other countries and/or different realities. Instruments for evaluation in the clinical practice have the ability to identify a potential problem, making it possible to concentrate human and material resources to prevent its outcome. In addition, they standardize the conduct to be applied in each situation and organize communication between the health team, which has a direct impact on the priority given to each patient. It is important to emphasize that, behind the use of culturally adapted predictive instruments, there is a vast history of people who have dedicated themselves to making plausible methods that show objectively and quickly the vulnerability of each patient ${ }^{(13)}$.

Pediatric patients, especially in intensive care units, are likely to develop $\mathrm{PI}^{(14)}$. Children's skin is characterized by being immature, thin, sensitive, fragile, poorly protected, and very delicate due to the great immaturity of the structures that constitute it, making it easily breakable(15-16).

In Brazil, the best-known instrument for predicting PI risk for pediatric patients is the Braden Q Scale (BQS)(17-18), which has good internal consistency (0.93); but its parameters were adapted from an adult version,
Braden Scale ${ }^{(19-20)}$, rather than developed specifically for the target population.

The Glamorgan Scale (GS), developed in $2009^{(21)}$, was created from a detailed questionnaire, based on a literature review on PI in the pediatric population, and extensive discussions with pediatric nurses experienced in the prevention and care of PI. From this questionnaire, a survey was carried out with 265 patients admitted to a children's hospital in England, with the objective of obtaining detailed data on their characteristics. After statistical analysis (Pearson's chi-square test), variables with statistically significant values $(p<0.01)$ emerged that were used in the composition of the GS.

This scale was designed to specifically assess children and adolescents from birth to 18 years of age, and is also suitable for preterm newborns ${ }^{(21)}$. While other risk assessment scales give similar weights to each subscale, the GS authors showed that some variables, such as mobility, are more significant than others, so they should be weighted according to their impact(21). In a comparative study(21-22), where both scales were applied to 336 pediatric patients, aged between one day of life and 18 years old, the GS showed greater sensitivity (98.4\%) and specificity (67.4\%) than the B-QS (67\% sensitivity and 65\% specificity).

When considering the importance of risk assessment for the development of PI in the context of care quality, as well as the better sensitivity and specificity of the GS, this study aimed to describe the methodological process of cultural adaptation of the GS to Brazilian Portuguese.

\section{Method}

This is a methodological study focused on the translation and cross-cultural adaptation of the Glamorgan Scale ${ }^{(21)}$, from English to Portuguese in the Brazilian context.

The GS is composed of nine items that receive scores according to the impairment presented. After assessing each of the nine items, the respective scores are added, obtaining a total score, which varies from 0 to 42 points, where the higher the score value, the greater the impairment and, consequently, the greater the risk of developing $\mathrm{PI}^{(21)}$.

According to the GS criteria, there are three risk stratifications for the total score: at risk $(10+)$, high risk (15+), and very high risk (20+). Patients should be evaluated daily, or if their clinical condition changes, or if they are transferred to another unit(21).

The translation and cross-cultural adaptation process, guided by the theoretical framework of Beaton, et al. (12), comprised the following stages (Figure 1): I: initial translation; II: synthesis of the translations; III: backtranslation; IV: committee of experts; V: pre-test; and VI: submission of the adapted version to the author for approval. 


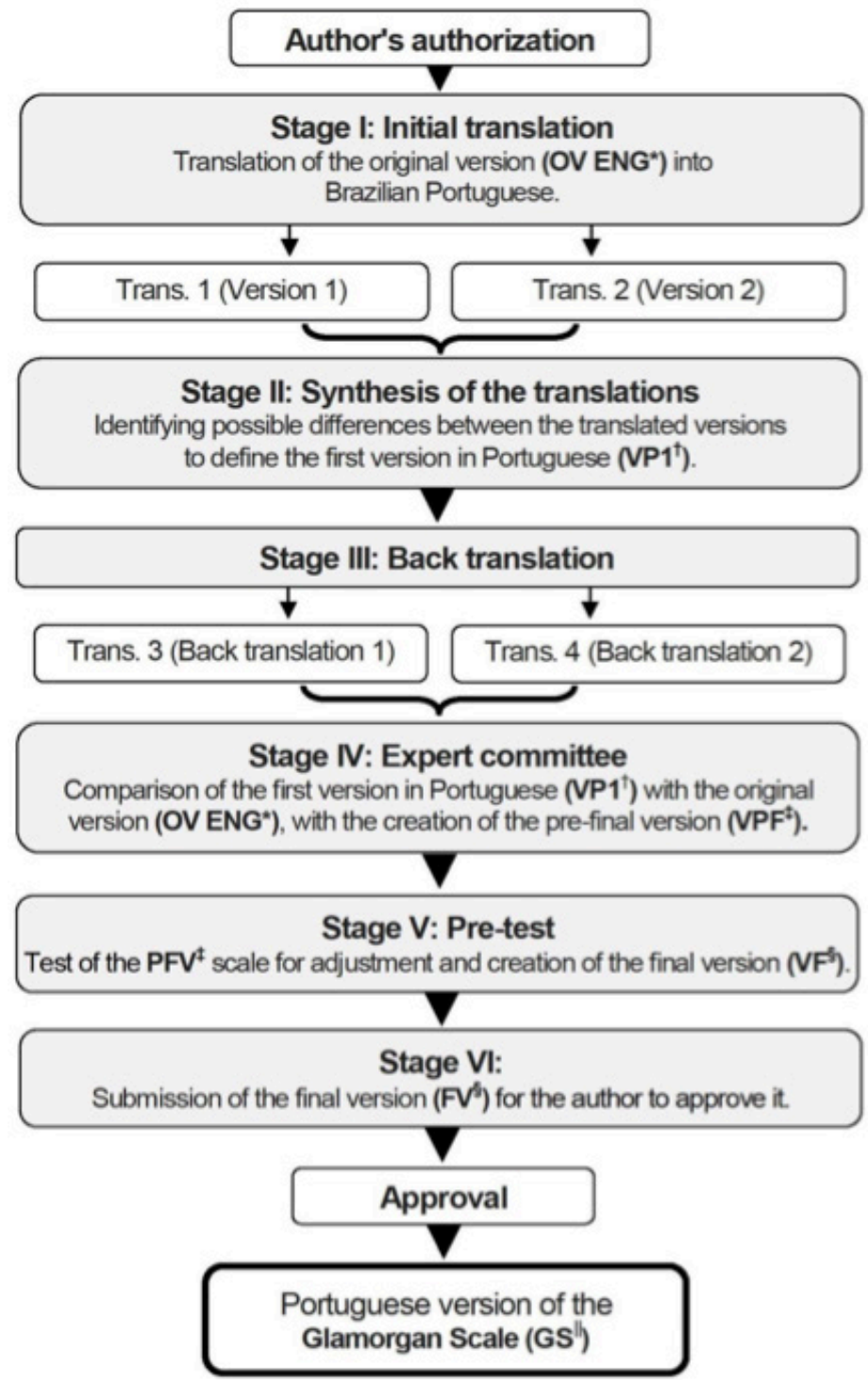

*OV ENG = Original version in English; ${ }^{\text {VP1 }}=$ First version in Portuguese; ${ }^{\text {PFV }}=$ Pre-final version; ${ }^{\text {§ FV }}=$ Final version; "GS = Glamorgan Scale Figure 1 - Flowchart of the methodological path of translation and cultural adaptation of the Glamorgan Scale into Portuguese in the Brazilian context. Botucatu, SP, Brazil, 2019

Stage I, which corresponds to the initial translation of the original version (OV ENG), was carried out independently by two translators (Trans. 1 and Trans. 2), who were bilingual (English/Portuguese) and had different profiles. Trans. 1, a nurse, had knowledge about the concepts assessed in the instrument, seeking equivalence from a clinical perspective; and Trans. 2 had no knowledge about the health field. After the independent translations, stage II was carried out, in which both translators (Trans. 1 and Trans. 2) established contact for discussion and synthesis of the versions (V1 and V2), resulting in the first Portuguese version (VP1).

In stage III, back-translation, another two translators (Trans. 3 and Trans. 4), who were bilingual (English/Portuguese) and had no training in the health field, did the back-translation of the VP1 instrument, that is, reverse translation to the original language generating two independent back-translations (RT1 and RT2). This is a validity check process, to make sure that the translated version is reflecting the same content as the original version.

In stage IV, the analysis was carried out by the committee of experts. For selection of the committee, it was aimed that the individuals were physicians, fluent in English, health professionals, had vast knowledge in the topic addressed, in addition to having specifically a stomatherapist component specialized in PI, and one had knowledge on the methodological process of cultural adaptation. Based on the translated and synthesized version (VP1), this material was evaluated and compared with the original version. The committee's main role was to compare the versions, evaluating them 
as for the semantic, idiomatic, cultural and conceptual equivalencies ${ }^{(12,23)}$. Semantic equivalence allows evaluating the meaning of words in order to preserve their original meaning; idiomatic equivalence evaluates the formulation of expressions and colloquialisms equivalent to the target language; cultural equivalence refers to everyday terms and situations that differ between the cultures; and conceptual equivalence refers to words that have cultural meanings ${ }^{(12,23)}$.

Thus, the experts evaluated and compared the versions, which resulted in the pre-final version (PFV). The relevance and representativeness of the items were assessed using the Content Validity Index (CVI), which measures the agreement among the evaluators. The adequacy of each item varied between adequate and not adequate, and a minimum value of 0.80 , or $80 \%$, was considered(24-25).

In the next stage $(\mathrm{V})$, the pre-test was performed, which consisted of the experimental application of the PFV of the scale by professional nurses. Preliminary instruments were delivered to each participant in this phase: the PFV, a script for applying the scale, and the document for recording the evaluation and possible suggestions. Seven intensive care nurses evaluated a group of patients in order to test the scale for understanding, clarity of the questions and answers, and the difficulties encountered by the professionals. The theoretical framework used suggests an ideal of 30 to 40 representatives for this stage ${ }^{12}$. However, the Glamorgan Scale is a clinimetric scale, where the end consumer is the nurse working in the Pediatric Intensive Care Unit. Thus, a convenience sample was selected with the following inclusion criteria: nurses, working in PICUs in high-complexity hospitals, and who were available to participate. Thus, seven nurses were selected, and the researchers premeditatedly waited for them to return their evaluations so as to identify the need to select more participants. Upon receiving the evaluations, compliance was observed, constituting sample saturation and making it unnecessary to expand the sample, since the seven evaluators have equal basic training and high understanding of the text. The suggestions made by the evaluators were accepted and a post-correction version was sent for approval, the final version (FV) thus coming to light.

This version was sent to the authors of the original version (stage VI), obtaining their approval.

In stages I to $\mathrm{V}$, reports were produced by each participating evaluator.

Prior to the research, authorization (personal communication) was granted by the authors who hold the rights to the scale. All the procedures carried out met the ethical principles, and the research was approved by the Research Ethics Committee under Opinion No. 1,908,776.

\section{Results}

In the translation and synthesis stages, the discrepancies found in the translations were related to words or terms with similar meanings in Brazil (e.g., without information and unknown; examining and evaluating; medical record and record). Thus, all the divergences found were studied and the translators, together with the researcher, chose the term they considered most usual in the context.

In the back-translation, versions RT1 and RT2 were identical in 13 statements (65\%), and the differences found were evaluated as being synonymous words. Thus, it was concluded that the back-translation versions corresponded to the original instrument.

The OV ENG and VP1 versions were sent to the committee of experts, so that they could make a comparison between them regarding the semantic, idiomatic, cultural and conceptual equivalences. The items' percentage of agreement was calculated based on the CVI, where all items obtained an agreement greater than $80 \%$ in the first evaluation round. In addition to the experts' assessment of whether the terms were adequate or not, they presented a report with suggestions for changes and their justifications. The experts suggested 16 words that should undergo changes in terms of textual equivalences, including: 12 semantic; 3 cultural; and 1 conceptual. After the experts' consensus, the suggestions were analyzed by the researchers, where all the recommendations regarding the textual content were deferred to create the pre-final version (PFV), with subsequent application in the pre-test.

After the stage of analysis by the specialists, the pretest was carried out, which included seven intensive care nurses. At this stage, doubts arose regarding the "mobility" set which, in its composition, has four sub-items, only one of which must be scored. In a report, the evaluators pointed out this issue as a potential confounder, and suggested the identification of the sub-items as being components of the large "mobility" set. In addition to this issue, it was also suggested to list the items for better viewing.

One of the evaluators, in the impaired peripheral perfusion item, highlighted the term "livedo" which, although appropriate, it is little known in the practice, which can hinder its interpretation. Thus, substitution was suggested, or the addition of the term mottled or mottling.

After reviewing these items, the final version (FV) was attained, which was sent to the authors of the original version for approval. They approved the FV of the scale, and the Brazilian version of the Glamorgan Scale was created, as shown below (Figure 2 ). 


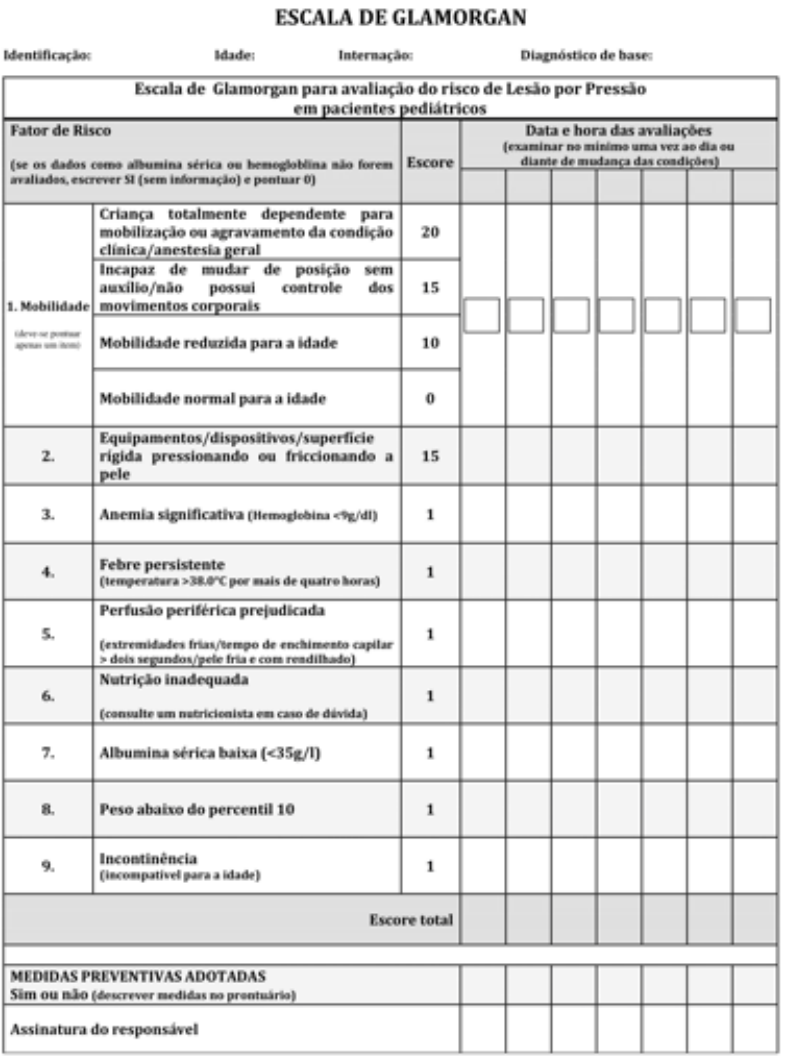

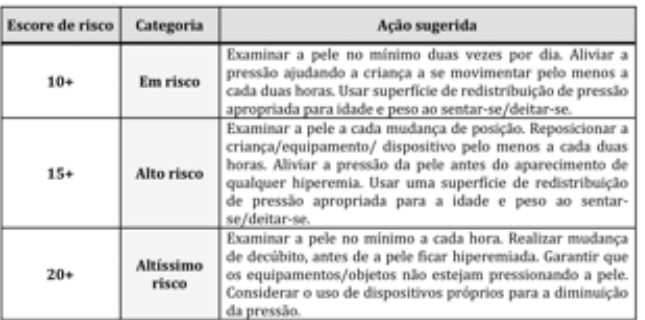

REGISTRO DE LESÃO POR PRESST̃O PEDIATRICA

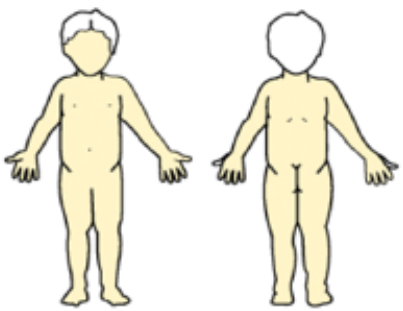

Utilize números para indicar no desenho acima a área lesionada, em seguida, use a tabela abaixo para identificar e descrever a lesảo por pressâo (data da identificaçăo da lesâo, local e estagio da lesso, resultado apdis tratamento, data da reavaliaçao e assinatura do avaliador).

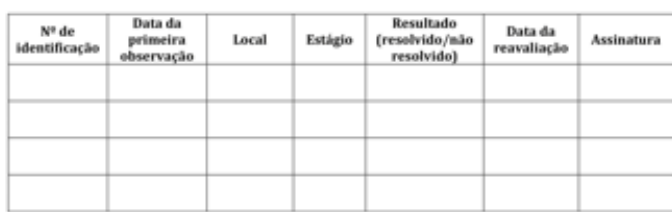

Figure 2 - Brazilian version of the Glamorgan Scale after the methodological process of translation and cultural adaptation. Botucatu, SP, Brazil, 2019

\section{Discussion}

The Nursing team plays a fundamental role in the early identification and implementation of strategies for the prevention of PI, highlighting the role of nurses, who seek new knowledge to support their practice. However, the prevention of PI is still a challenge for Nursing.

A study carried out in a public hospital in Brazil applying the B-QS in a PICU pointed out a high risk for the development of PI in $87 \%$ of the patients and development of $24 \mathrm{PIs}^{(14)}$, thus highlighting the importance of implementing preventive protocols ${ }^{(26)}$ and predictive instruments for the effective prevention of this condition. Another study confirmed that all patients who developed PIs had in fact a high risk alert when applying the scale(27).

In view of the proven high risk, it is necessary for the professionals to know about the predictive risk instruments. Currently, the B-QS is the most used and most reported instrument in the scientific literature for pediatric patients admitted to critical care ${ }^{(11,28)}$. As previously stated, the B-QS is an effective instrument; however, the GS was specifically developed for the study population, having greater accuracy, greater predictive capacity, and can even be applied to a broadest age group ( 0 to 18 years old) ${ }^{(29)}$. For this reason, the crosscultural adaptation of this new instrument was carried out.
The translation and cross-cultural adaptation of instruments are important processes to ensure the accuracy and reliability of the measurements obtained by health professionals and researchers. Once created in a particular country, an instrument can be used in different countries. For this proposal, an adequate translation and cross-cultural adaptation must be carried out, taking into account the characteristics of the context in which it will be inserted. The process of cultural adaptation of instruments is a legitimate procedure, capable of promoting the exchange of knowledge among researchers, being also a financially accessible and important method for comparing the results of studies using the same tool(30-31).

There are numerous strategies for the process of cross-cultural adaptation, ranging from simple translation by researchers to the most detailed process ${ }^{(12)}$. During the process, all the stages of this study sought to adjust the instrument to the target population, and efforts were directed so that this tool could be applied in all Brazilian hospitals.

The analysis by the committee of experts regarding the textual equivalences was essential to ensure that the new instrument is understandable by nurses. The experts made significant suggestions, making the instrument clearer and culturally appropriate for Brazilian Portuguese. Evidence shows that research 
studies evaluated by a committee of experts have better indexes of adjustments of the models, with more adequate content for the proposed context ${ }^{(32-33)}$. All the suggestions regarding the textual content were accepted for the creation of the pre-final version (PFV).

The application of the pre-test allowed for a critical overview of the instrument, where doubts arose on how to score the "mobility" item. Following the participants' suggestions, the word "mobility" was added in front of its subcategories, and below the phrase "only one item must be scored".

Therefore, it was not necessary to change the number of items that make up the scale or the way it is evaluated; thus, the Brazilian version of the Glamorgan Scale is also composed of nine items, with a total score from 0 to 42 .

The translation of an instrument in a region of Brazil, a country with a homogeneous language, can be considered appropriate for the entire national territory. It is also believed that the new version of the instrument can be used by professionals from other countries whose native language is Portuguese.

Considering that the GS was specifically designed for children and adolescents from birth to 18 years of age, and that it has greater specificity and sensitivity than the B-QS, this study contributes to the field of health and nursing by bringing a specific tool to assist the professional nurse in the risk assessment of PIs in the pediatric population, allowing specific preventive interventions to be incorporated in the assistance provided to high-risk patients.

As a limitation, it should be noted that the scale has not yet undergone the process of cultural adaptation in another country, making it difficult to discuss and compare the results.

\section{Conclusion}

This study allowed for the translation and crosscultural adaptation of the Glamorgan Scale in the Brazilian Portuguese version, contributing to the advancement of knowledge and evidence-based practice, insofar as, in a relevant manner, it provides an instrument capable of evaluating the risk of critical pediatric patients developing PIs.

\section{References}

1. Edsberg LE, Black JM, Goldberg M, McNichol L, Moore L, Sieggreen M. Revised National Pressure Ulcer Advisory Panel Pressure Injury Staging System: Revised Pressure Injury Staging System. J Wound Ostomy Continence
Nurs. 2016 Nov/Dec;43(6):585-97. doi: http://dx.doi. org/10.1097/WON.0000000000000281

2. Bauer K, Rock K, Nazzal M, Jones O, Qu W. Pressure Ulcers in the United States' Inpatient Population From 2008 to 2012: Results of a Retrospective Nationwide Study. Ostomy Wound Manag. [Internet]. 2016 Nov [cited Jan 20, 2020];62(11):30-8. Available from: https://www. ncbi.nlm.nih.gov/pubmed/27861135?dopt=Abstract\&u tm_source $=$ dlvr.it\&utm_medium $=$ twitter

3. Wong D, Holtom P, Spellberg B. Osteomyelitis Complicating Sacral Pressure Ulcers: Whether or Not to Treat With Antibiotic Therapy. Clin Infect Dis. 2019 Jan;68(2):33842. doi: http://dx.doi.org/10.1093/cid/ciy559

4. Dreyfus J, Gayle J, Trueman P, Delhougne G, Siddiqui A. Assessment of Risk Factors Associated With HospitalAcquired Pressure Injuries and Impact on Health Care Utilization and Cost Outcomes in US Hospitals. Am J Med Qual. 2018 Jul;33(4):348-58. doi: http://dx.doi. org/10.1177/1062860617746741

5. Payne D. Strategies to support prevention, identification and management of pressure ulcers in the community. $\mathrm{Br}$ J Community Nurs. 2016 Jun;Suppl:S10, S12-5, S18. doi: http://dx.doi.org/10.12968/bjcn.2016.21.Sup6.S10 6. Padula WV, Delarmente BA. The national cost of hospital-acquired pressure injuries in the United States. Int Wound J. 2019 Jun;16(3):634-40. doi: http://dx.doi. org/10.1111/iwj.13071

7. Wilson L, Kapp S, Santamaria N. The direct cost of pressure injuries in an Australian residential aged care setting. Int Wound J. 2019 Feb;16(1):64-70. doi: http:// dx.doi.org/10.1111/iwj.12992

8. Conselho Regional de Enfermagem do Estado de São Paulo. Cartilha dos 10 passos da segurança do paciente. [Internet]. São Paulo: REBRAENSP; 2010 [Acesso 20 jan 2020]. Disponível em: https://portal.coren-sp.gov.br/ sites/default/files/10_passos_seguranca_paciente_0.pdf 9. Ministério da Saúde (BR). Portaria de Consolidação nº 5, de 28 de setembro de 2017. [Internet]. Diário Oficial da União, 3 out 2017 [Acesso 20 jan 2020]. Disponível em: http://portalarquivos2.saude.gov.br/images/pdf/2018/ marco/29/PRC-5-Portaria-de-Consolida----o-n---5--de28-de-setembro-de-2017.pdf

10. Hödl M, Voithofer C. Pressure ulcer risk assessment and preventive measures in mobile /chairfast /bedfast hospital patients. Pflege. 2019 Aug;32(4):181-7. doi: http://dx.doi.org/10.1024/1012-5302/a000678

11. Ferreira MKM, Gurgel SS, Lima FET, Cardoso MVLML, Silva VM. Instruments for the care of pressure injury in pediatrics and hebiatrics: an integrative review of the literature. Rev. Latino-Am. Enfermagem. 2018;26:e3034. doi: http://dx.doi.org/10.1590/1518-8345.2289.3034 12. Beaton DE, Bombardier C, Guillemin F, Ferraz MB. Guidelines for the process of cross-cultural adaptation of 
self-report measures. Spine. 2000 Dec;25(24):3186-91. doi: http://dx.doi.org/10.1097/00007632-20001215000014

13. Gardona RGB, Barbosa DA. The importance of clinical practice supported by health assessment tools. Rev Bras Enferm. 2018 Jul-Aug;71(4):1815-6. doi: http://dx.doi. org/10.1590/0034-7167-2018710401

14. MC Vocci, CMB Fontes, LPF Abbade. Pressure injury in the pediatric population: cohort study using the Braden $\mathrm{Q}$ scale. Adv Skin Wound Care. 2018 Oct;31(10):456-61. doi: http://dx.doi.org/10.1097/01.ASW.0000542529.94557.0a 15. Mack MC, Chu MR, Tierney NK, Ruvolo E Jr, Stamatas GN, Kollias N, et al. Water-holding and transport properties of skin stratum corneum of infants and toddlers are different from those of adults: studies in three geographical regions and four ethnic groups. Pediatr Dermatol. 2016 May;33(3):275-82. doi: http://dx.doi. org/10.1111/pde. 12798

16. Walters RM, Khanna P, Chu M, Mack MC. Developmental changes in skin barrier and structure during the first 5 years of life. Skin Pharmacol Physiol. 2016;29(3):111-8. doi: http://dx.doi.org/10.1159/000444805.

17. Curley MAQ, Razmus IS, Roberts KE, Wypij D. Predicting pressure ulcer risk in pediatric patients: the Braden Q Scale. Nurs Res. 2003 Jan-Feb;52(1):22-33. doi: http://dx.doi.org/10.1097/00006199-200301000-00004 18. Maia ACAR, Pellegrino DMS, Blanes L, Dini GM, Ferreira LM. Portuguese translation and validation of the Braden Q scale for predicting pressure ulcer risk in pediatric patients. Rev Paul Pediatr. 2011;29(3):405-14. doi: http:// dx.doi.org/10.1590/S0103-05822011000300016

19. Bergstrom N, Braden BJ, Laguzza A, Holman V. The Braden Scale for predicting pressure sore risk. Nurs Res. [Internet]. 1987 Jul-Aug [cited 20 jan 2020];36(4):20510. Available from: https://insights.ovid.com/ nurres/198707000/00006199-198707000-00002

20. Serpa LS, Santos VLCG, Campanili TCF, Queiroz M. Predictive Validity of the Braden Scale for Pressure Ulcer Risk in Critical Care Patients. Rev. Latino-Am. Enfermagem. 2011 Jan-Feb;19(1):50-7. doi: http:// dx.doi.org/10.1590/s0104-11692011000100008

21. Willock J, Baharestani MM, Anthony D. The development of the Glamorgan paediatric pressure ulcer risk assessment scale. J Wound Care. 2009;18(1):17-21. doi: http://dx.doi.org/10.12968/jowc.2009.18.1.32135 22. Willock J, Habiballah L, Long D, Palmer K, Anthony D. A comparison of the performance of the Braden $Q$ and the Glamorgan paediatric pressure ulcer risk assessment scales in general and intensive care paediatric and neonatal units. J Tissue Viability. 2016 May;25(2):11926. doi: https://doi.org/10.1016/j.jtv.2016.03.001

23. Guillemin F, Bombardier C, Beaton D. Cross-cultural adaptation of health-related quality of life measures: literature review and proposed guidelines. J Clin Epidemiol. 1993 Dec;46(12):1417-32. doi: http://dx.doi. org/10.1016/0895-4356(93)90142-n

24. Grant JS, Davis LL. Selection and use of content experts for instrument development. Res Nurs Health. 1997 Jun;20(3):269-74. doi: http://dx.doi.org/10.1002/ (sici)1098-240x(199706)20:3<269: :aid-nur9>3.0.co;2-g 25. Polit DF, Beck CT. The content validity index: are you sure you know what's being reported? Critique and recommendations. Res Nurs Health. 2006 Oct;29(5):48997. doi: http://dx.doi.org/10.1002/nur.20147

26. Vasconcelos JMB, Caliri MHL. Nursing actions before and after a protocol for preventing pressure injury in intensive care. Esc Anna Nery. 2017 Jan;21(1):e20170001. doi: http://dx.doi.org/ 10.5935/1414-8145.20170001

27. Vocci MC, Toso LAR, Fontes CMB. Application of the Braden $Q$ scale at a pediatric intensive care unit. J Nurs UFPE On Line. 2017;11(1):165-72. doi: http://dx.doi. org/10.5205/reuol.9978-88449-6-1101201720

28. Liao Y, Gao G, Mo L. Predictive accuracy of the Braden $\mathrm{Q}$ Scale in risk assessment for paediatric pressure ulcer: A meta-analysis. Int J Nurs Sci. 2018;5(4):419-26. doi: 10.1016/j.ijnss.2018.08.003

29. Anthony D, Willock J, Baharestani M. A comparison of Braden Q, Garvin and Glamorgan risk assessment scales in paediatrics. J Tissue Viability. 2010 Aug;19(3):98-105. doi: http://dx.doi.org/10.1016/j.jtv.2010.03.001

30. Alshehri A, Lohman E, Daher NS, Bahijri K, Alghamdi A, Altorairi N, et al. Cross-cultural adaptation and psychometric properties testing of the Arabic anterior knee pain scale Med Sci Monit. 2017 Apr 1;23:1559-82. doi: http://dx.doi.org/10.12659/msm.901264

31. Gomes A, Ximenes L, Mendes E, Teixeira O, Joventino $E$, Javorski M. Translation and cultural adaptation of the self-efficacy and their child's level of asthma control scale: Brazilian version. Texto Contexto Enferm. 2016;25(3):e2950015. doi: http://dx.doi. org/10.1590/0104-07072016002950015

32. Epstein J, Osborne RH, Elsworth GR, Beaton DE, Guillemin F. Cross-cultural adaptation of the Health Education Impact Questionnaire: experimental study showed expert committee, not back-translation, added value. J Clin Epidemiol. 2015 Apr;68(4):360-9. doi: http:// dx.doi.org/10.1016/j.jclinepi.2013.07.013

33. Machado RDS, Fernandes ADBF, Oliveira ALCB, Soares LS, Gouveia MTO, Silva GRFD. Cross-cultural adaptation methods of instruments in the nursing area. Rev Gaucha Enferm. 2018 Jul;39:e20170164. doi: http://dx.doi. org/10.1590/1983-1447.2018.2017-0164 


\section{Authors' Contribution:}

Study concept and design: Marcelli Cristine Vocci, Cassiana Mendes Bertoncello Fontes, Luciana Patricia Fernandes Abbade. Obtaining data: Marcelli Cristine Vocci, Cassiana Mendes Bertoncello Fontes, Luciana Patricia Fernandes Abbade. Data analysis and interpretation: Marcelli Cristine Vocci, Cassiana Mendes Bertoncello Fontes, Luciana Patricia Fernandes Abbade. Statistical analysis: Marcelli Cristine Vocci, Cassiana Mendes Bertoncello Fontes, Luciana Patricia Fernandes Abbade. Obtaining financing: Marcelli Cristine Vocci, Cassiana Mendes Bertoncello Fontes, Luciana Patricia Fernandes Abbade. Drafting the manuscript: Marcelli Cristine Vocci, Cassiana Mendes Bertoncello Fontes, Luciana Patricia Fernandes Abbade. Critical review of the manuscript as to its relevant intellectual content: Marcelli Cristine Vocci, Cassiana Mendes Bertoncello Fontes, Luciana Patricia Fernandes Abbade.

All authors approved the final version of the text.

Conflict of interest: the authors have declared that there is no conflict of interest. Creative Commons (CC BY).

This license lets others distribute, remix, tweak, and build upon your work, even commercially, as long as they credit you for the original creation. This is the most accommodating of licenses offered. Recommended for maximum dissemination and use of licensed materials. 